\title{
Continental-scale patterns in benthic invertebrate diversity: insights from the MacroBen database
}

\author{
P. E. Renaud ${ }^{1, *}$, T. J. Webb, A. Bjørgesæter, I. Karakassis, M. Kędra, M. A. Kendall, C. Labrune, \\ N. Lampadariou, P. J. Somerfield, M. Włodarska-Kowalczuk, E. Vanden Berghe, S. Claus, I. F. Aleffi, \\ J. M. Amouroux, K. H. Bryne, S. J. Cochrane, S. Dahle, S. Degraer, S. G. Denisenko, T. Deprez, \\ C. Dounas, D. Fleischer, J. Gil, A. Grémare, U. Janas, A. S. Y. Mackie, R. Palerud, H. Rumohr, \\ R. Sardá, J. Speybroeck, S. Taboada, G. Van Hoey, J. M. Węsławski, P. Whomersley, M. L. Zettler
}

${ }^{1}$ Akvaplan-niva, Polar Environmental Centre, 9296 Tromsø, Norway

\begin{abstract}
Latitudinal clines in species diversity in limnic and terrestrial habitats have been noted for well over a century and are consistent across many taxonomic groups. However, studies in marine systems over the past 2 to 3 decades have yielded equivocal results. We conducted initial analyses of the MarBEF (EU Network of Excellence for Marine Biodiversity and Ecosystem Function) database to test for trends in local and regional diversity over the latitudinal extent of European continental-shelf waters $\left(36^{\circ}\right.$ to $\left.81^{\circ} \mathrm{N}\right)$. Soft-sediment benthic macrofauna exhibit little evidence of a latitudinal cline in local $(\alpha-)$ diversity measures. Relationships with water depth were relatively strong and complex. Statistically significant latitudinal trends were small and positive, suggesting a modest increase in diversity with latitude once water-depth covariates were removed. These results are consistent regardless of whether subsets of the database were used, replicates were pooled, or component taxonomical groups were evaluated separately. Local and regional diversity measures were significantly and positively correlated. Scientific cooperation through data-sharing is a powerful tool with which to address fundamental ecological and evolutionary questions relating to large-scale patterns and processes.
\end{abstract}

KEY WORDS: Biodiversity $\cdot$ North Atlantic $\cdot$ Mediterranean $\cdot$ Arctic $\cdot$ Baltic $\cdot$ Continental shelf $\cdot$ Benthos · Latitude

Resale or republication not permitted without written consent of the publisher

\section{INTRODUCTION}

Biodiversity research has expanded in the past 2 to 3 decades from the realm of systematics and biology to the fields of biogeography and evolution. This trend has resulted in renewed interest in describing and recording taxa, with corresponding studies describing regional and global biodiversity patterns, developing new techniques with which to measure diversity, proposing mechanisms responsible for generation and maintenance of these patterns, and experimentally investigating the functional significance of biodiversity (e.g. Clarke \& Warwick 1998, Willig et al. 2003, Gage 2004, Hillebrand 2004, Solan et al. 2006, and references therein). These timely studies come as the earth's ecosystems are confronted with natural and human-induced environmental change and its impact on biotic systems. Informed management and conservation strategies require a solid understanding of underlying biodiversity patterns and their consequences for system functioning.

Renewed efforts to document marine biodiversity were probably initiated by Grassle \& Maciolek (1992), who suggested that there may be as many as 10 million 
benthic infaunal species yet to be identified in the deep sea. Since then, there have been many studies investigating diversity patterns, with special focus on how biodiversity varies with water depth and latitude. Many studies have identified an increase in diversity with water depth through the bathyal zone, followed by a decrease in abyssal and hadal zones (e.g. Rex 1981, Levin et al. 2001). Latitudinal patterns have been less clear, but, in general, diversity of benthic communities or of component groups has been shown to decline with increasing latitude in the northern hemisphere (Rex et al. 1993, 2000, Boucher \& Lambshead 1995, Culver \& Buzas 2000, Mokievsky \& Azovsky 2002, Gage et al. 2004, Hillebrand 2004, Witman et al. 2004, Renaud et al. 2006). Other regional studies, however, have failed to detect this pattern or even showed regionally opposite trends (Heip et al. 1992, Kendall \& Aschan 1993, Dauvin et al. 1994, Kendall 1996, Clarke \& Lidgard 2000, Lambshead et al. 2000, Ellingsen \& Gray 2002, Rees et al. 2007), and patterns in some taxonomic or trophic groups are not replicated in others (Azovsky 2000, Ellingsen 2001, Hillebrand 2004, Karakassis et al. 2006).

These conflicting results suggest that multiple factors are responsible for generating and maintaining biodiversity of the benthos. Instead of being viewed as a problem, these varying patterns can be used to help detect which factors/mechanisms are important for different conditions, scales, and taxa. Proposed mechanisms can be divided into 2 principle categories: ecological and evolutionary. Ecological mechanisms include temperature, primary productivity, sediment heterogeneity, and life-history strategy (e.g. Huston 1979, Etter \& Grassle 1992, Lambshead et al. 2000, 2002, Roy et al. 2000, Levin et al. 2001, Renaud et al. 2006), while evolutionary factors include tectonic history, climate fluctuation, and the ages of taxonomic clades (e.g. Svavarsson et al. 1993, Crame 1997, 2001, Culver \& Buzas 2000, Clarke \& Crame 2003, Gage 2004, Włodarska-Kowalczuk et al. 2004). Spatial variability in these mechanisms determine biodiversity patterns, and varying degrees of interaction among them may be responsible for the differing observations recorded in the literature.

Patterns of species richness in the global avifauna appear to be well explained by models incorporating both spatial variation in available energy and the likelihood of a species reaching potentially suitable areas (Storch et al. 2006). Simple geometrical constraints may also play a role in concentrating species richness towards the midpoint of a domain (the 'mid-domain effect' or MDE, reviewed in Colwell et al. 2004). However, the predictive power of MDE models is critically dependent on a priori divisions between domains and knowledge of species ranges (Hawkins et al. 2005,
Zapata et al. 2005, Storch et al. 2006). They are, therefore, likely to be of limited utility in marine systems where such information is largely absent. Determining the relative importance of ecological, evolutionary, and statistical (geometrical) factors to the generation and maintenance of observed patterns in species richness remains a fundamental challenge for biodiversity studies.

Before mechanisms can be assessed, however, it is critical to evaluate the basis for the patterns that have been observed. Some studies have included extensive local sampling and meta-analysis, while others are based on limited sampling. Sample-collection techniques have not always been comparable, and intensive sampling may be restricted over narrow geographical ranges. An appropriate dataset must contain many samples collected by comparable procedures across a wide geographical domain: an effort not afforded through normal research projects - or even many careers. Marine Biodiversity and Ecosystem Functioning (MarBEF: www.marbef.org), an EU Network of Excellence, has made major strides to remedy these biases by compiling a database (MacroBen) comprised of datasets from across the European domain. These datasets from marine benthic studies can be used for a variety of investigations of biodiversityrelated questions.

In the present study, we perform initial analyses of this database in reference to European-scale gradients in benthic biodiversity. With the power of such a large collection of comparable data, we can investigate whether there is support for previously identified trends in local $(\alpha-)$ biodiversity with water depth and latitude. We will pursue this for the entire benthic faunal communities, and for important component groups. In the process, we test for the effects of variable sampling effort represented in the database. Confidently identifying latitudinal or depth patterns can inform future investigations of underlying mechanisms responsible for their generation and maintenance.

\section{DATA AND METHODS}

MacroBen database. Integrating individual datasets into large databases, to enable analysis on Europewide scales, was one of the core objectives of the MarBEF network. Different databases were planned, each to capture comparable data for integrative analyses. The initial database included with data from softbottom benthic biotopes. A major effort was undertaken to harmonize the taxonomy across the different datasets: all names were matched, both for spelling and synonymy, with the European Register of Marine Species (ERMS) (Vanden Berghe et al. 2009, this 
Theme Section). Raw data were retained whenever possible to allow maximum flexibility during analyses. Most data providers also furnished geographical and physical data.

The finalized dataset was distributed as an Access file to all data providers. Included in the database were several tools to extract data and to calculate basic statistics and diversity coefficients. The final database contained 465354 distribution records, from 7481 taxa and 23113 stations. There were 43 individual datasets. A full description of the database is given in Vanden Berghe et al. (2009).

Latitudinal-gradient database. In effort to work with the most inclusive, yet most comparable dataset possible, we performed initial filtering on the MacroBen database. The extracted working database for latitudinal-gradient studies of soft-sediment benthos included: (1) quantitative data, (2) non-juvenile animal taxa, (3) organisms identified to species level, (4) non-colonial animals (Bryozoa, Hydrozoa, Porifera excluded), (5) samples collected after 1980 (for taxonomic comparability reasons), (6) subtidal stations only, (7) samples collected with $0.1 \mathrm{~m}^{2}$ grabs only, (8) samples sieved on max. $1 \mathrm{~mm}$ mesh, and (9) multiple records from the same location, if available.

While these criteria do not eliminate some potential problems (e.g. unequal effort per sampling location or latitude), they do make initial analyses more straightforward. Preliminary analyses of even this modified database suggested that some analyses should be performed following additional filtering (e.g. Fig. 1A,C).

Initially, samples were pooled for each $1^{\circ}$ of latitude. This retains information contained in the database and allows calculation of a ' $\gamma$-richness' estimate for each $1^{\circ}$ of latitude. Species-area and species accumulation curves were then constructed by plotting pooled ' $\gamma$ richness' by 2 measures of sampling effort, area sampled and number of individuals collected, for each $1^{\circ}$ of latitude. These are not the traditional species-area or species accumulation curves, but instead are plotted in this way to test for effects of sampling intensity. ' $\gamma$-richness' residuals of least-squares regressions (log-transformed variables) were plotted against latitude to determine whether regional $\gamma$-diversity changed with latitude after accounting for sampling intensity (Clarke \& Lidgard 2000). A multiple linear regression technique was also used to test for effect of latitude on regional diversity accounting for latitudinal differences in area and number of individuals sampled.

The $2 \alpha$-diversity indices that we based most of our analyses on are the number of species, $S$, and Hurlbert's expected number of species calculated for 50 individuals, $\mathrm{E}\left(\mathrm{S}_{50}\right)$. Species richness is better than equitability indices in the study of large-scale patterns, and $\mathrm{E}\left(\mathrm{S}_{\mathrm{n}}\right)$ is robust to sample size variations (Boucher \&
Lambshead 1995). In addition, $\mathrm{E}\left(\mathrm{S}_{\mathrm{n}}\right)$ incorporates some of the evenness component of diversity. Analyses were conducted for each sample in the database for the entire faunal assemblage, and initially on samples pooled by $5^{\circ}$ increments of latitude.

$S$ and $\mathrm{E}\left(\mathrm{S}_{50}\right)$ were plotted against latitude and water depth to determine whether relationships prevalent in the literature were consistent with our data. We tested for these relationships in several ways. First, linear and quadratic (unimodal) models were fitted to the plots of $S$ and $\mathrm{E}\left(\mathrm{S}_{50}\right)$ with latitude and water depth. LOWESS (locally-weighted scatterplot smoothing) functions (Quinn \& Keough 2002) were also fitted to these data, with $\alpha$ set to 0.75 (i.e. the neighborhood for each locally weighted regression includes $3 / 4$ of all points). The shape of the LowESs smooth is useful for characterizing the shape of the relationship, and for assessing whether the fitted linear or quadratic model adequately captures this shape. After finding that the water-depth distribution of our sample locations was not random with respect to latitude, we controlled for this covariance by running multiple linear regressions with water depth and latitude as factors. This works well if the underlying relationship is linear, but because quadratic regressions had a better fit for much of the data, we also plotted the residuals from the quadratic regressions of each diversity index with water depth against the quadratic residuals of latitude with water depth. Similar analyses have been performed using residuals from linear regressions (Lambshead et al. 2001, Renaud et al. 2006). Since the Baltic Sea exhibited relatively low biodiversity compared to other areas at that latitude, we performed a second filtering of the dataset by excluding Baltic stations to determine whether this biased our findings for or against identifying latitudinal trends. We then repeated the regression analyses on the dataset with the Baltic data excluded, and on major taxonomic groups (polychaetes, mollusks, and arthropods) from this new dataset.

In addition to species richness and evenness, it is also relevant to ask whether variation in different axes of diversity may be contributing to observed patterns. Taxonomic distinctness, $\Delta^{+}$, a measure of relatedness among species (Warwick \& Clarke 2001), was calculated for the subset of samples containing 5 or more species. Taxonomic relationships were determined from ERMS. Values were calculated for whole assemblages, annelids, crustaceans, and mollusks, and analyzed using linear and multiple linear regression.

Finally, we wanted to ensure the validity of using $\alpha$ diversity statistics to evaluate regional diversity patterns. Therefore, we calculated Chao1 and Chao2, and $S_{\text {obs }} \gamma$-diversity estimators for each dataset and plotted those values against the average $S$ value for those 
datasets. If these indices are positively correlated, then local diversity patterns are likely to reflect diversity on regional scales. Analyses were performed using the JMP-In (SAS Institute), PRIMER (Clarke \& Gorley 2006), Statistica (StatSoft), R (R Development Core Team 2005), and EstimateS (Colwell 1997) software packages.

Table 1. Summary statistics on component datasets. For additional information see Vanden Berghe et al. (2009, this Theme Section)

\begin{tabular}{|llcr|}
\hline Dataset & Location & $\begin{array}{c}\text { Depth } \\
(\mathrm{m})\end{array}$ & $\begin{array}{r}\text { No. of } \\
\text { records }\end{array}$ \\
\hline Baltic Sea & & & \\
70 & Baltic Sea & 23 & 998 \\
Gd & Baltic Sea & $30-100$ & 87 \\
Ze & Baltic Sea & $11-90$ & 3433 \\
Ze & Gulf of Finland & & 7 \\
Mediterranean Sea & & \\
Do & Aegean Sea & $10-60$ & 2057 \\
Do & Eastern Basin & & 453 \\
Gr & Western Basin & $10-50$ & 4912 \\
Lm & Adriatic Sea & $5-25$ & 6838 \\
North Atlantic Ocean & & \\
Hs & Hornsund, Svalbard & $25-203$ & 375 \\
NP & Celtic Sea & $35-96$ & 252 \\
NP & English Channel & & 309 \\
NP & North Sea & & 365 \\
o2 & Barents Sea & $59-379$ & 1403 \\
o4 & North Sea & $71-434$ & 26166 \\
o4 & Norwegian Sea & & 19585 \\
o5 & Celtic Sea & $7-130$ & 1018 \\
o5 & Irish Sea/St. George's & & 2936 \\
& Channel & & \\
o6 & Barents Sea & $160-374$ & 2262 \\
o6 & Norwegian Sea & & 7460 \\
o7 & Pechora Sea & $7-207$ & 2106 \\
o8 & Franz Josef Land & $52-312$ & 1717 \\
Ug & North Sea & $35-40$ & 6626 \\
North Sea & North Sea & & \\
o3 & Nor & \\
& & & \\
& & & \\
\hline
\end{tabular}

\section{RESULTS}

Initial filtering of the MarBEF database resulted in a file containing over 3200 samples and over 1 million individuals from nearly 2200 species. This represents 16 individual datasets covering areas of the Adriatic, Mediterranean, Baltic, Irish, North, Barents, and Pechora Seas, as well as the European Atlantic coast (Table 1), from $36^{\circ}$ to $81^{\circ} \mathrm{N}$. Depths of stations varied considerably with latitude, with stations in low and high latitudes being generally shallower than stations at mid-latitudes (Table 2). Sample water depth was not recorded for one of the datasets, so samples sizes for regressions (Table 3 ) against water depth were slightly lower than diversity-latitude relationships.

Regional (by latitude) species diversity varied significantly with the area and number of individuals sampled ( $p<0.05 ; \mathrm{r}^{2}=0.58$ and 0.60 , respectively; Fig. $1 \mathrm{~A}, \mathrm{C})$. Plots of the diversity residuals from these regressions against latitude showed that $\gamma$-diversity did not vary with latitude $(p>0.98$ and $p>0.27$, respectively; Fig. 1B,D). Multiple linear regression analysis also indicated that this measure of regional diversity did not vary with latitude after controlling for area or number of individuals sampled $(p>0.98$ and $p>0.19$, respectively).

Both $S$ and $\mathrm{E}\left(\mathrm{S}_{50}\right)$ showed unimodal trends with water depth, with maximum values occurring at intermediate water depths $\left(\mathrm{r}^{2}=0.22\right.$ and $0.41, \mathrm{p}<0.0001$, respectively; Table 3, Fig. 2A,B). This trend was the same, whether models were fitted to point data or to data pooled into $50 \mathrm{~m}$ depth increments, and the LOWESS smooths show that the second-order polynomial models capture the shape of the relationships well. Unimodal relationships, albeit fairly weak, were also suggested between latitude and both $S$ and $\mathrm{E}\left(\mathrm{S}_{50}\right)$ $\left(\mathrm{r}^{2}=0.21\right.$ and $0.33, \mathrm{p}<0.0001$ respectively; Fig. $2 \mathrm{C}, \mathrm{D}$, Table 3), although the shapes of both the fitted polynomial models and the Lowess smooths suggest that

Table 2. Number of stations sampled by depth and latitude zone

\begin{tabular}{|c|c|c|c|c|c|c|c|c|c|c|}
\hline $\begin{array}{l}\text { Depth } \\
\text { (m) }\end{array}$ & $35-40$ & $40-45$ & $45-50$ & $50-55$ & $\begin{array}{c}\text { Latitude }\left({ }^{\circ} \mathrm{N}\right) \\
55-60\end{array}$ & $60-65$ & $65-70$ & $70-75$ & $75-80$ & $>80$ \\
\hline $0-50$ & 55 & 76 & 148 & 518 & 107 & 4 & 4 & 0 & 13 & 0 \\
\hline $50-90$ & 1 & 16 & 0 & 40 & 81 & 2 & 1 & 5 & 11 & 4 \\
\hline $90-150$ & 0 & 0 & 0 & 32 & 44 & 100 & 0 & 1 & 17 & 0 \\
\hline $150-200$ & 0 & 0 & 0 & 0 & 0 & 14 & 2 & 7 & 2 & 1 \\
\hline $200-250$ & 0 & 0 & 0 & 0 & 0 & 7 & 6 & 5 & 1 & 1 \\
\hline $250-300$ & 0 & 0 & 0 & 0 & 0 & 18 & 7 & 22 & 0 & 0 \\
\hline $300-350$ & 0 & 0 & 0 & 0 & 0 & 40 & 13 & 22 & 2 & 1 \\
\hline $350-400$ & 0 & 0 & 0 & 0 & 0 & 9 & 11 & 3 & 0 & 0 \\
\hline $400-450$ & 0 & 0 & 0 & 0 & 0 & 0 & 2 & 0 & 0 & 0 \\
\hline Total & 56 & 92 & 148 & 590 & 232 & 194 & 46 & 65 & 46 & 7 \\
\hline
\end{tabular}



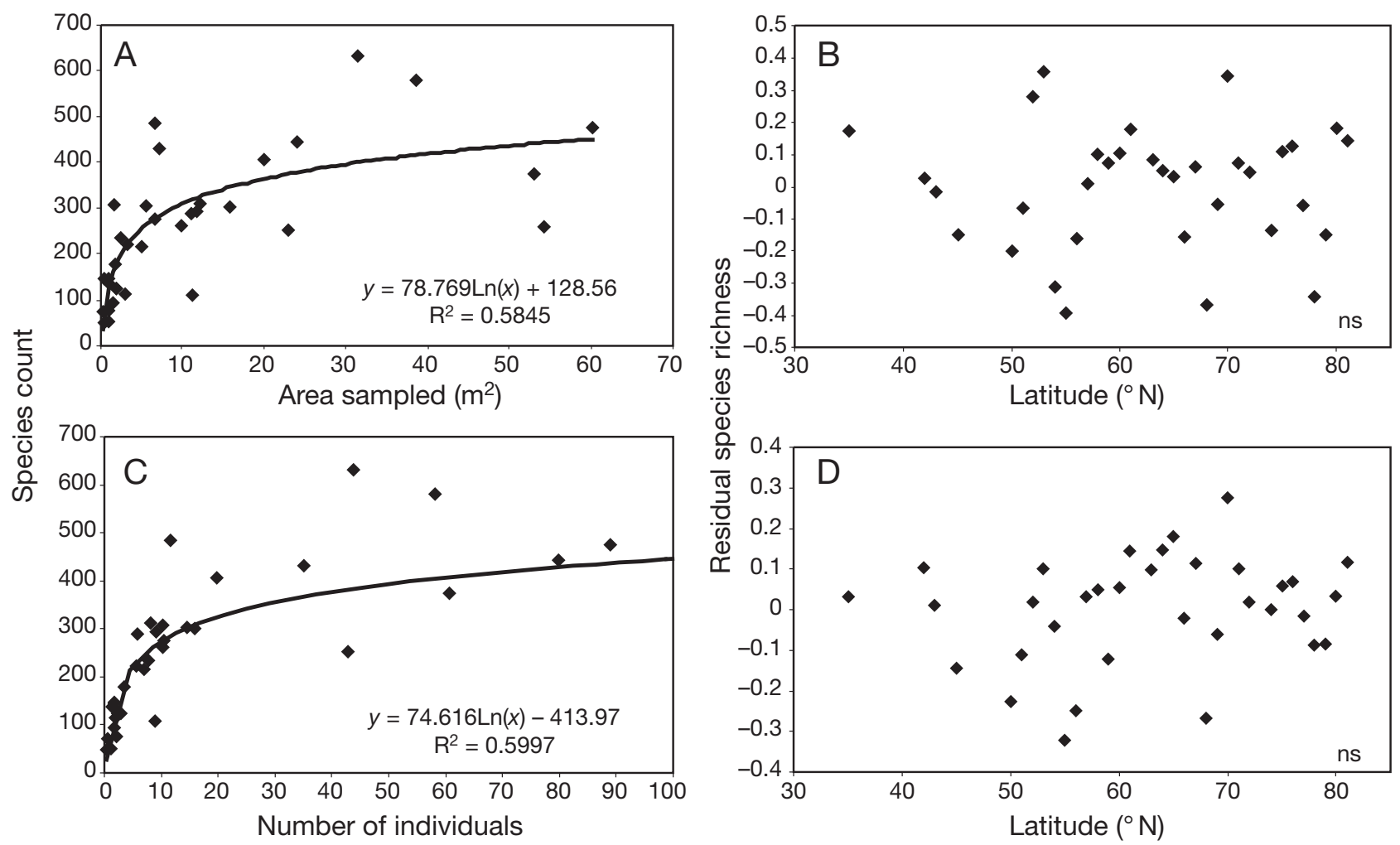

Fig. 1. Regional species richness (species count) pooled by degree of latitude plotted against 2 measures of sampling efforts (A): area sampled and (C) number of individuals sampled. Linear regression of log-transformed data in these 2 plots was performed and the residuals are plotted against latitude in (B) and (D)

Table 3. Linear, quadratic, and multiple linear regression (MLR) analyses of total number of species, $S$, and Hurlbert's expected number of species calculated for 50 individuals, $\mathrm{E}\left(\mathrm{S}_{50}\right)$, against depth and latitude. $\mathrm{r}^{2}$ values are presented for each model, or for each predictor in MLR. Regressions of diversity-depth residuals in latitude-depth residuals are also presented. Since quadratic relationships explained most of the variation, residuals (resid) of these regressions (and not the linear regressions) are used. $\mathrm{p}$-values for quadratic regressions are for the quadratic term in the equation; na: not applicable

\begin{tabular}{|c|c|c|c|c|c|}
\hline \multirow[t]{2}{*}{ Regression } & \multirow[t]{2}{*}{ Type } & \multicolumn{2}{|c|}{ Entire dataset } & \multicolumn{2}{|c|}{ Baltic removed } \\
\hline & & $\mathrm{p}$ & $\mathrm{r}^{2}$ & $\mathrm{p}$ & $\mathrm{r}^{2}$ \\
\hline $\mathrm{S} \times$ latitude & Linear & 0.0001 & 0.184 & 0.0001 & 0.178 \\
\hline $\mathrm{S} \times$ latitude & Quadratic & 0.0001 & 0.211 & 0.0001 & 0.212 \\
\hline $\mathrm{S} \times$ depth & Linear & 0.0001 & 0.028 & 0.0001 & 0.013 \\
\hline $\mathrm{S} \times$ depth & Quadratic & 0.0001 & 0.218 & 0.0001 & 0.185 \\
\hline $\mathrm{S} \times$ latitude, depth & MLR & 0.0001 & $0.095,0.003$ & 0.0001 & $0.082,0.009$ \\
\hline Quadratic resid: $\mathrm{S}$ - depth $\times$ latitude - depth & Linear & 0.0008 & 0.005 & 0.0001 & 0.007 \\
\hline $\mathrm{E}\left(\mathrm{S}_{50}\right) \times$ latitude & Linear & 0.0001 & 0.300 & 0.0001 & 0.297 \\
\hline $\mathrm{E}\left(\mathrm{S}_{50}\right) \times$ latitude & Quadratic & 0.0001 & 0.331 & 0.0001 & 0.337 \\
\hline $\mathrm{E}\left(\mathrm{S}_{50}\right) \times$ depth & Linear & 0.0001 & 0.267 & 0.0001 & 0.235 \\
\hline $\mathrm{E}\left(\mathrm{S}_{50}\right) \times$ depth & Quadratic & 0.0001 & 0.413 & 0.0001 & 0.376 \\
\hline $\mathrm{E}\left(\mathrm{S}_{50}\right) \times$ latitude, depth & MLR & 0.0001 & $0.032,0.267$ & 0.0001 & $0.037,0.236$ \\
\hline Quadratic resid: $\mathrm{E}\left(\mathrm{S}_{50}\right)-$ depth $\times$ latitude - depth & Linear & 0.801 & na & 0.779 & na \\
\hline
\end{tabular}

the main pattern is a relatively abrupt increase north of about $55^{\circ}$, with little change thereafter. Results were similar when the data were pooled into $5^{\circ}$ increments of latitude. To remove the potentially confounding effect of water depth on the latitudinal trend, 2 techniques were employed. (1) Multiple linear regression analyses were performed, and these indicated that both water depth and latitude contributed significantly, but latitude only explained 9.5 and $3.2 \%$ of the variability in $S$ and $\mathrm{E}\left(\mathrm{S}_{50}\right)$, respectively, while water depth explained 0.3 and $27 \%$, respectively ( $p<0.02$ for all relationships; Table 3). (2) To remove the effect of 

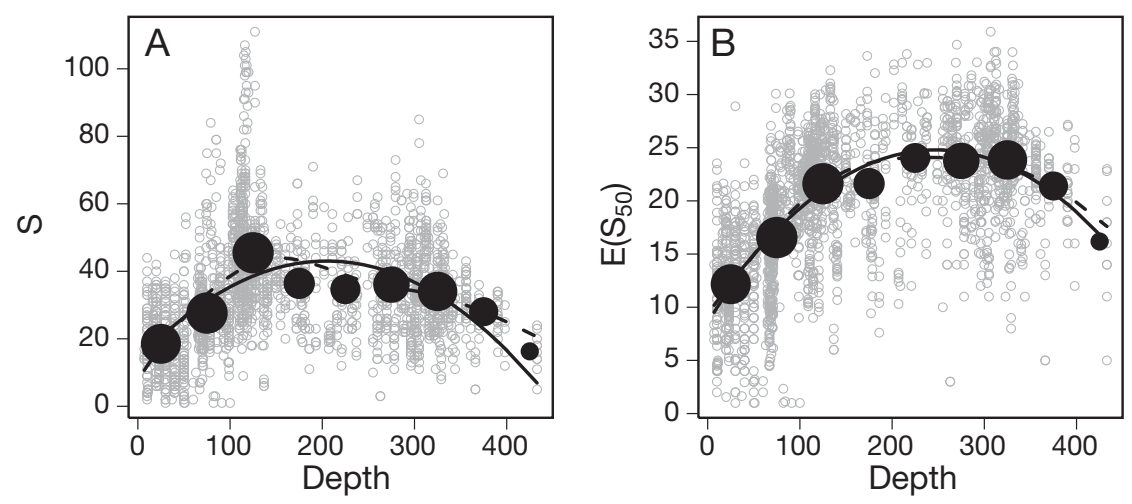

Fig. 2. (A,C) Species richness, $S$, and (B,D) Hurlbert's expected number of species calculated for 50 individuals, $\mathrm{E}\left(\mathrm{S}_{50}\right)$, plotted against $(\mathrm{A}, \mathrm{B})$ depth and $(\mathrm{C}, \mathrm{D})$ latitude. Station-level values shown as grey circles. Black symbols represent means for $50 \mathrm{~m}$ depth bands or $1^{\circ}$ latitudinal bands, with size proportional to the number of stations. Solid lines represent fitted 2nd order polynomial regression models, which in all cases provided a significantly better fit to the data than simple linear models (see Table 3 ). Dashed lines are Lowess smooths Polynomial regression and Lowess models were fitted to the station-level (point) data
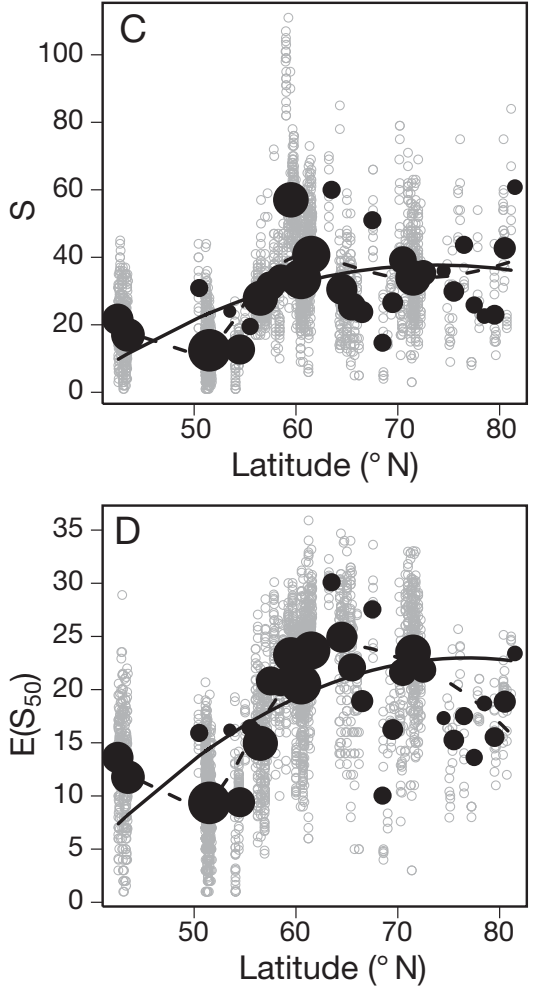

water depth for quadratic relationships, residuals of the diversity-depth (quadratic) relationships were plotted against the latitude-depth (quadratic) residuals. This result indicated that latitude had little or no effect on either $S$ or $\mathrm{E}\left(\mathrm{S}_{50}\right)$. The linear regression of the residuals for $S$ was significant ( $<<0.0001$; Table 3 ) but had $\mathrm{r}^{2}<0.005$, while for $\mathrm{E}\left(\mathrm{S}_{50}\right)$ the regression was not significant ( $\mathrm{p}>0.80$; Table 3$)$.

Both $S$ and $\mathrm{E}\left(\mathrm{S}_{50}\right)$ for the Baltic datasets were significantly lower than that for the other datasets (Fig. 3; ANOVA followed by Tukey-Cramer HSD: $p<0.05)$. The multiple regression analyses and residual plots were recalculated after omitting the Baltic datasets, with nearly identical results: little effect of latitude was seen on either diversity measure (Fig. 4, Table 3). Similar analyses of the 3 most abundant taxonomic groups indicated weak or no latitudinal pattern in diversity following residual regressions (Fig. 5, Table 4). Results varied for the different taxonomic groups, with water depth having a much greater effect on polychaete and arthropod diversity than on mollusk diversity (Table 4). Multiple linear regression showed a significant relationship with water depth for these 2 groups, with $\mathrm{r}^{2}$ ranging from 0.21 to 0.39 (Table 4). Similar analyses showed that latitude did explain almost $20 \%$ of the variability in mollusk diversity (Table 4). In all these analyses, the explanatory power of latitude was very weak, but where significant, slopes were positive, i.e. suggesting increasing $\alpha$-diversity with latitude.
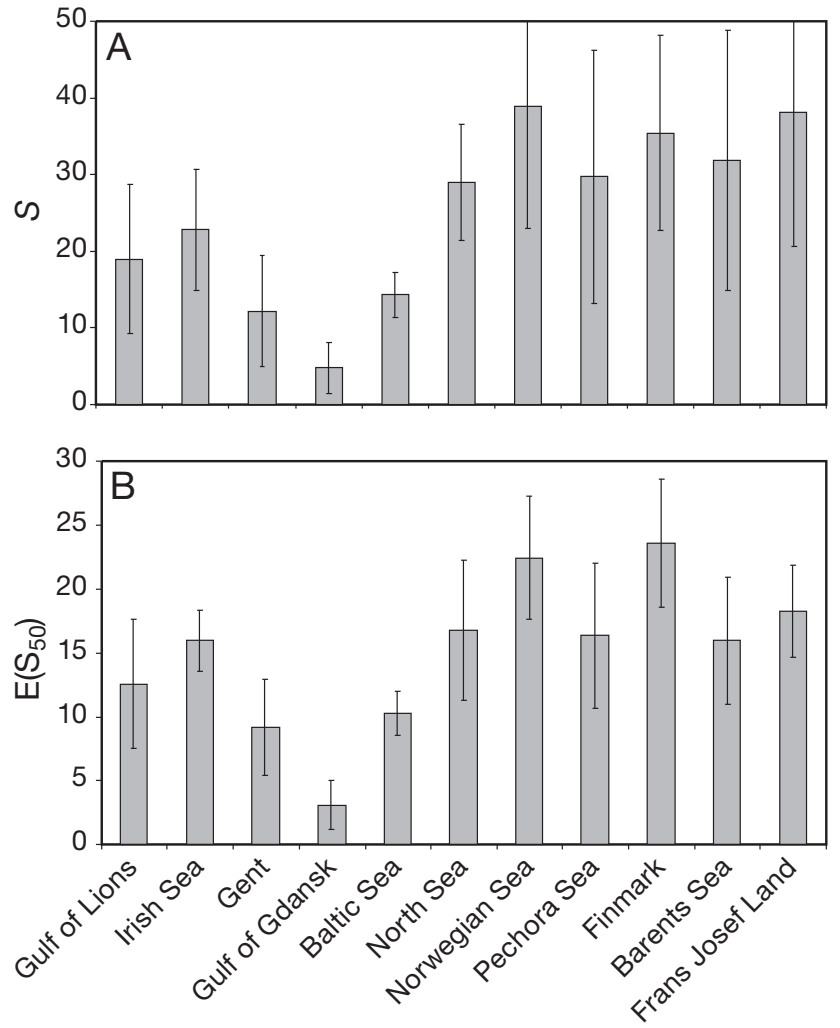

Fig. 3. (A) Total species richness, $S$, and (B) Hurlbert's expected number of species calculated for 50 individuals, $\mathrm{E}\left(\mathrm{S}_{50}\right)$, in order of increasing latitude. Note low values for Baltic Sea datasets (Gulf of Gdansk, Baltic Sea). Error bars represent SD 

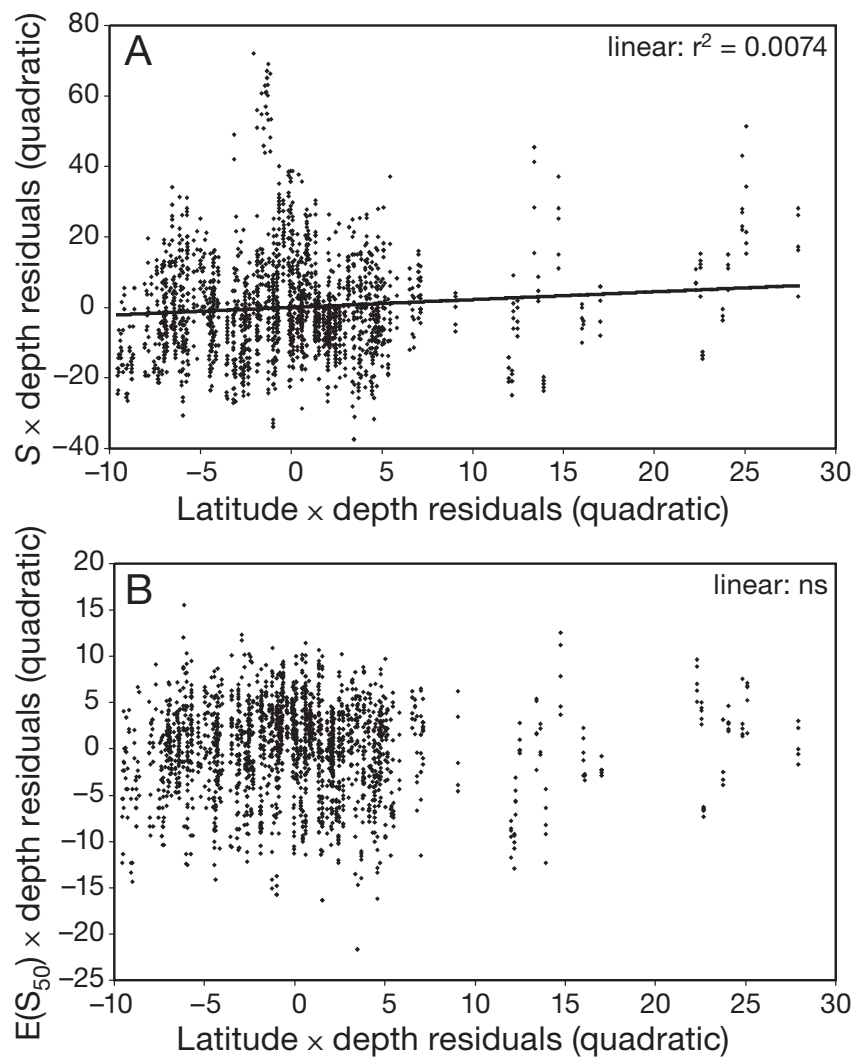

Fig. 4. (A) Residuals of the species richness, $S$, and (B) Hurlbert's expected number of species calculated for 50 individuals, $\mathrm{E}\left(\mathrm{S}_{50}\right)$, vs. depth regression against the residuals of the latitude vs. depth regression. Residuals are taken from the quadratic regressions. Baltic Sea stations removed. ns = linear regression not significant

Taxonomic distinctness also showed a weak but significant relationship with water depth $\left(\mathrm{r}^{2}=0.041\right)$, with samples from the middle of the range tending to have lower values (Fig. 6), rather than higher values as shown by $S$ and $\mathrm{E}\left(\mathrm{S}_{50}\right)$. The p-values for this, and all results for taxonomic distinctness, were $<0.001$. After this effect was removed, the residuals showed a weak but significant $\left(r^{2}=0.025\right)$ increasing trend with latitude (Fig. 6). The extent to which these patterns reflect subtle shifts in the phyletic composition of assemblages is difficult to assess, but different phyla show different patterns (Ellingsen et al. 2005). While annelids showed a positive relationship with water depth $\left(r^{2}=0.212\right)$, tending to be lower at mid-depths, the remaining relationship with latitude, while significant $\left(\mathrm{r}^{2}=0.035\right)$, was one of decreased values in the middle of the latitudinal range (Fig. 7). Weaker but similar patterns $\left(r^{2}=0.15\right.$ and 0.012 , respectively) were apparent for crustaceans (data not shown). In contrast, mollusks showed weak relationships with both water depth $\left(\mathrm{r}^{2}=0.009\right)$ and latitude $\left(\mathrm{r}^{2}=0.045\right)$, and indicated a tendency to increase towards the north (Fig. 7).
The Chao1 $\gamma$-diversity estimator and the mean (by dataset) $\alpha$-diversity index, $S$, showed a positive relationship ( $\mathrm{p}<0.05 ; \mathrm{r}^{2}=0.39$; Fig. 8). Chao 1 was also highly correlated with $S_{\text {obs }}$ and Chao $2 \gamma$-diversity estimators $\left(\mathrm{p}<0.05 ; \mathrm{r}^{2}>0.98\right.$, data not shown).

\section{DISCUSSION}

\section{Large-scale patterns in biodiversity}

Initial analyses of the MarBEF database indicated little evidence for strong latitudinal trends in diversity $\left(S, \mathrm{E}\left[\mathrm{S}_{50}\right]\right.$, or $\left.\Delta^{+}\right)$of benthic shelf fauna along the European continental shelf. Where statistically significant trends existed, they were generally weak $\left(\mathrm{r}^{2}<0.1\right)$ and positive, i.e. diversity increased with latitude (Figs. 2, $4,5 \& 6$; Table 3). Findings were consistent whether interactive effects with water depth were removed by multiple linear regression or through regressions of residuals. Lack of a decline in diversity with latitude on continental-shelf soft substrates has also been documented by others (Kendall \& Aschan 1993, Dauvin et al. 1994, Kendall 1996, Ellingsen \& Gray 2002), but contradicts findings from the deep Arctic basin by Deubel (2000) and Renaud et al. (2006). The last 2 studies were conducted over shorter latitudinal ranges or beyond the depth range of the present study, however, and with generally low sample density. The present results agree with the observation of Thorson (1957) that, while there may be a latitudinal gradient in diversity for hard-substrate epifauna, similar patterns for soft-sediment benthos are not well-founded. Hillebrand (2004) found the latitudinal gradients in diversity to be particularly weak for benthic infauna in a meta-analysis of $>100$ marine studies from around the world and from shallow water to the deep sea. Extrapolating results from diversity studies of epifauna to infaunal communities has also proven to be untenable with respect to Antarctic shelf fauna (WłodarskaKowalczuk et al. 2006).

The trend toward a poleward decrease in marine biodiversity has gained widespread acceptance over the past $30 \mathrm{yr}$, with similar results observed from deepsea, estuarine tidal flat, and shallow subtidal hardsubstrate communities, and from taxonomic groups as diverse as foraminifera, nematodes, gastropods, bivalves, and crustaceans (e.g. Rex et al. 1993, 2000, Boucher \& Lambshead 1995, Roy et al. 1998, Crame 2000, Culver \& Buzas 2000, Attrill et al. 2001, Gage et al. 2004, Witman et al. 2004). Patterns are not simple in all of these studies, however (e.g. peaks in diversity at mid-latitude in both Atlantic and Pacific gastropods, Roy et al. 1998; eastern versus western North Atlantic diversity levels in a variety of fish and invertebrates, 

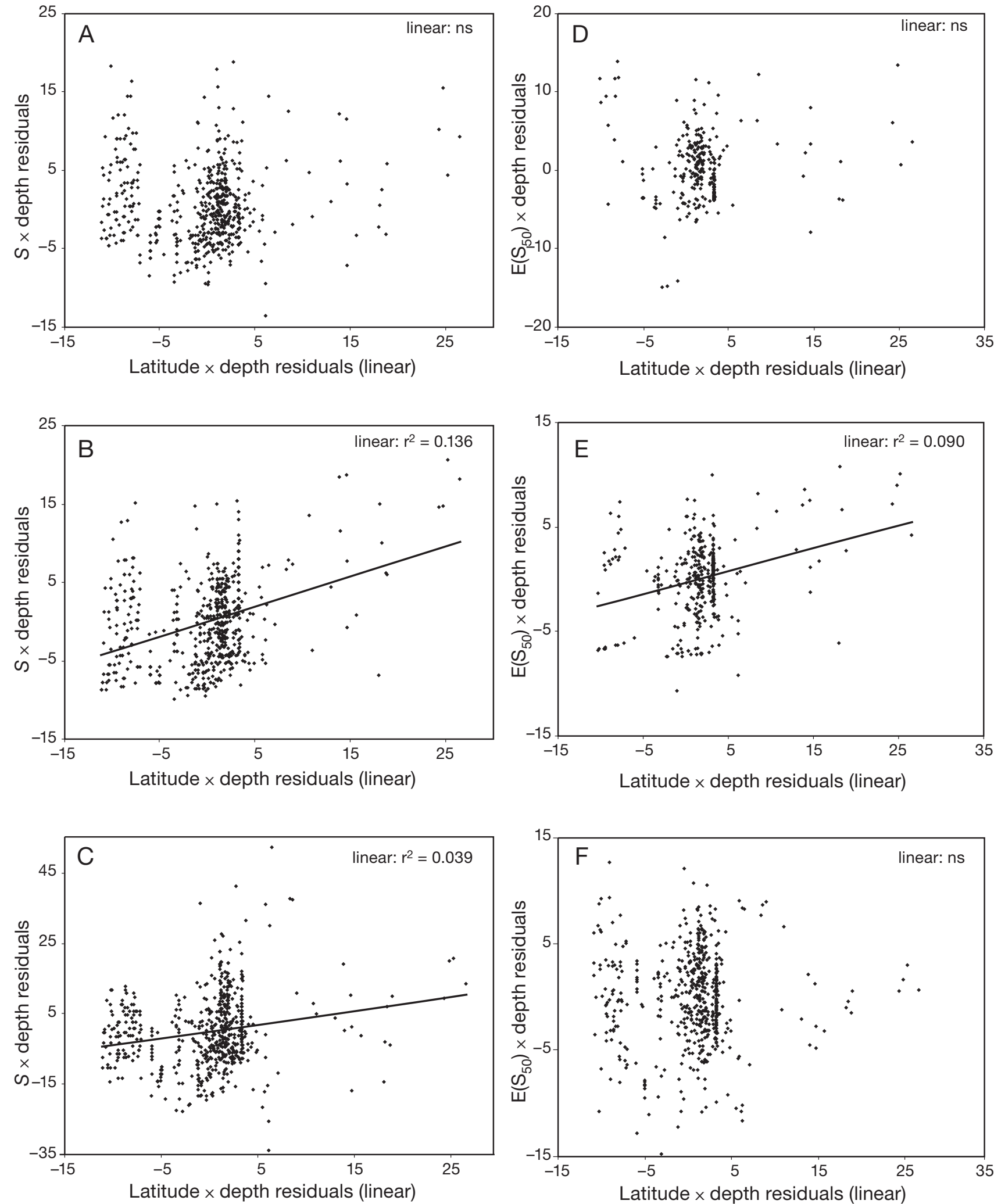

Fig. 5. (A-C) Residuals of the species richness, $S$, and (D-F) Hurlbert's expected number of species calculated for 50 individuals, $\mathrm{E}\left(\mathrm{S}_{50}\right)$, vs. depth regression against the residuals of the latitude vs. depth regression. Data exclude Baltic Sea samples and are for the 3 most common taxonomic groups: $(\mathrm{A}, \mathrm{D})$ arthropods, $(\mathrm{B}, \mathrm{E})$ mollusks, and $(\mathrm{C}, \mathrm{F})$ polychaetes. Regression results expressed as 
Table 4. Statistical results for linear regressions of diversity indices on latitude and depth for the 3 most common taxonomic groups: polychaetes, arthropods, and mollusks. Analyses were performed following removal of Baltic data. Regressions of linear residuals (Resid) are also shown, as in Table $3 . S=$ species richness; $\mathrm{E}\left(\mathrm{S}_{50}\right)=$ Hurlbert's expected number of species calculated for 50 individuals; $\mathrm{MLR}=$ multiple linear regression; $\mathrm{ns}=$ not significant

\begin{tabular}{|c|c|c|c|c|c|c|c|}
\hline \multirow[t]{2}{*}{ Regression } & \multirow{2}{*}{ Type } & \multicolumn{2}{|c|}{ _ Polychaetes } & \multicolumn{2}{|c|}{ —Arthropods — } & \multicolumn{2}{|c|}{ _Mollusks - } \\
\hline & & $\mathrm{p}$ & $\mathrm{r}^{2}$ & $\mathrm{p}$ & $\mathrm{r}^{2}$ & $\mathrm{p}$ & $\mathrm{r}^{2}$ \\
\hline$S \times$ latitude & Linear & 0.0001 & 0.326 & 0.0001 & 0.137 & 0.0001 & 0.209 \\
\hline$S \times$ depth & Linear & 0.0001 & 0.384 & 0.0001 & 0.246 & 0.0001 & 0.089 \\
\hline$S \times$ latitude, depth & MLR & 0.0001 & $0.024,0.385$ & 0.0001 & ns, 0.247 & 0.0001 & $0.210,0.005$ \\
\hline Resid: $S$ - depth $\times$ latitude - depth & Linear & 0.0001 & 0.039 & 0.860 & $\mathrm{~ns}$ & 0.0001 & 0.137 \\
\hline $\mathrm{E}\left(\mathrm{S}_{50}\right) \times$ latitude & Linear & 0.0001 & 0.194 & 0.0001 & 0.173 & 0.0001 & 0.200 \\
\hline $\mathrm{E}\left(\mathrm{S}_{50}\right) \times$ depth & Linear & 0.0001 & 0.321 & 0.0001 & 0.304 & 0.0001 & 0.118 \\
\hline $\mathrm{E}\left(\mathrm{S}_{50}\right) \times$ latitude, depth & MLR & 0.0001 & $\mathrm{~ns}, 0.322$ & 0.0001 & ns, 0.307 & 0.0001 & $0.202, \mathrm{~ns}$ \\
\hline Resid: $\mathrm{E}\left(\mathrm{S}_{50}\right)-$ depth $\times$ latitude - depth & Linear & 0.777 & ns & 0.996 & ns & 0.0001 & 0.090 \\
\hline
\end{tabular}
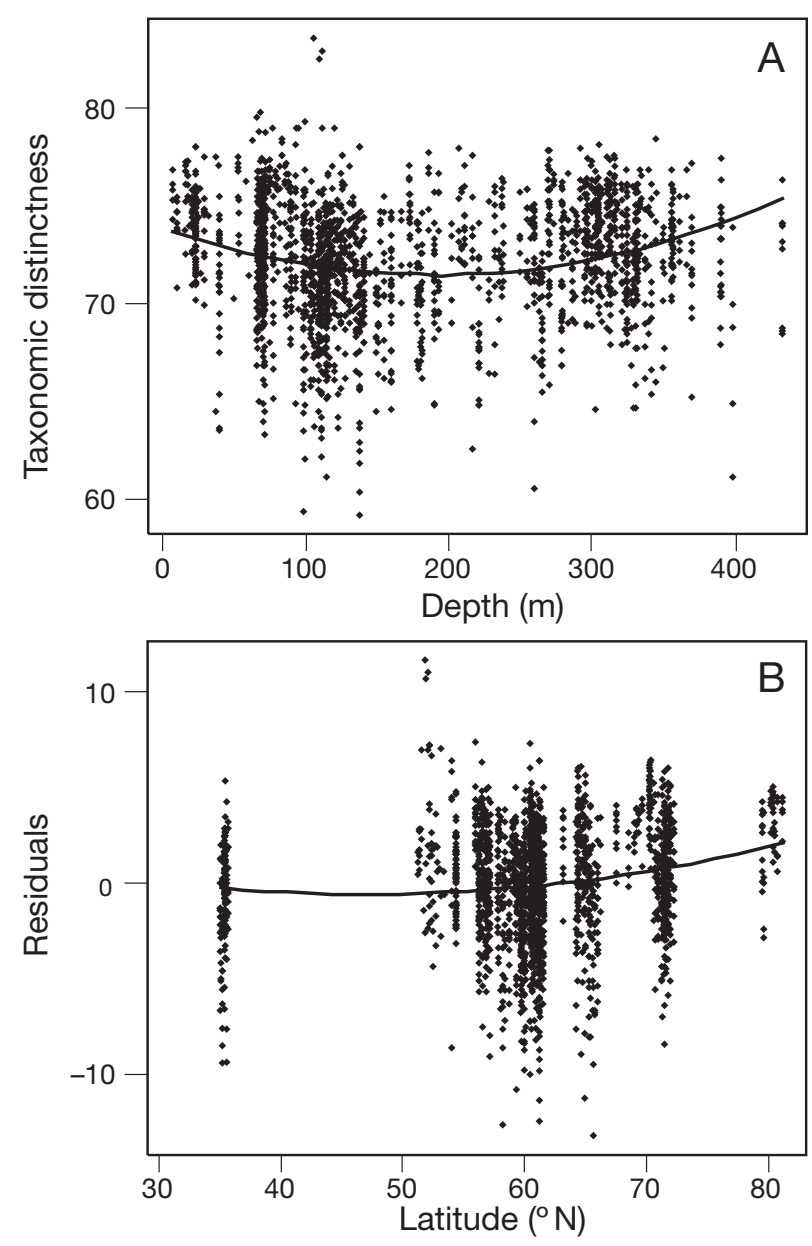

Fig. 6. (A) Average taxonomic distinctness against depth and (B) the residuals from this relationship plotted against latitude. Fitted lines from polynomial regressions

MacPherson 2002). Why then are the results from soft-sediment shelf habitats so equivocal, and perhaps even opposite? First, this may be a consequence of the limited latitudinal range observed in the present study, spanning only about $45^{\circ}$ of latitude, while many of the other studies sampled sites from the equator or even further south. Roy et al. (1998) identified a strong decrease in mollusk diversity with latitude, but much of that decrease took place between the equator and $35^{\circ} \mathrm{N}$, a zone we miss entirely with our sampling range. Conversely, few of the other studies cover stations north of around $60^{\circ} \mathrm{N}$, whereas the present study has fully half of its stations above that latitude. Sampling high-latitude areas is critical to evaluating not only patterns, but also mechanisms, as several theories postulate history of ice cover and connectivity of ocean basins as contributing to the observed pattern (e.g. Rex et al. 1993, Crame 1997, Gray 2002). Finally, several studies showing decreasing diversity with latitude in different taxonomic groups sampled the same stations (Rex et al. 1993, 2000, Gage et al. 2004), suggesting the possibility that the similar results represent a feature of the combination of stations sampled and perhaps not an underlying global pattern. Sampling density in the present study is unprecedented compared with other studies, reducing the potential problem of site-specific features having disproportionately large effects on observed patterns.

Investigation of biodiversity patterns over such a large spatial scale does present some problem in interpretation of the results. Some of the most obvious comparisons to be made are with high-resolution surveys of smaller components of this range. These smaller, regional studies (e.g. Heip et al. 1992, Ellingsen 2001, Ellingsen \& Gray 2002, Rees et al. 2007), however, examine, implicitly or explicitly, impacts of environmental or ecological gradients on community assemblage from a single species pool. For example, there is an increase in biodiversity from south to north in the North Sea (Heip et al. 1992, Rees et al. 2007). The North Sea results, from stations spanning $>11^{\circ}$ latitude, are consistent in repeated surveys, and coincide with gradients in depth, bottom temperature, and salinity. Communities in the North Sea, however, are likely assembled from a regional species pool that is distinct from the pool sup- 

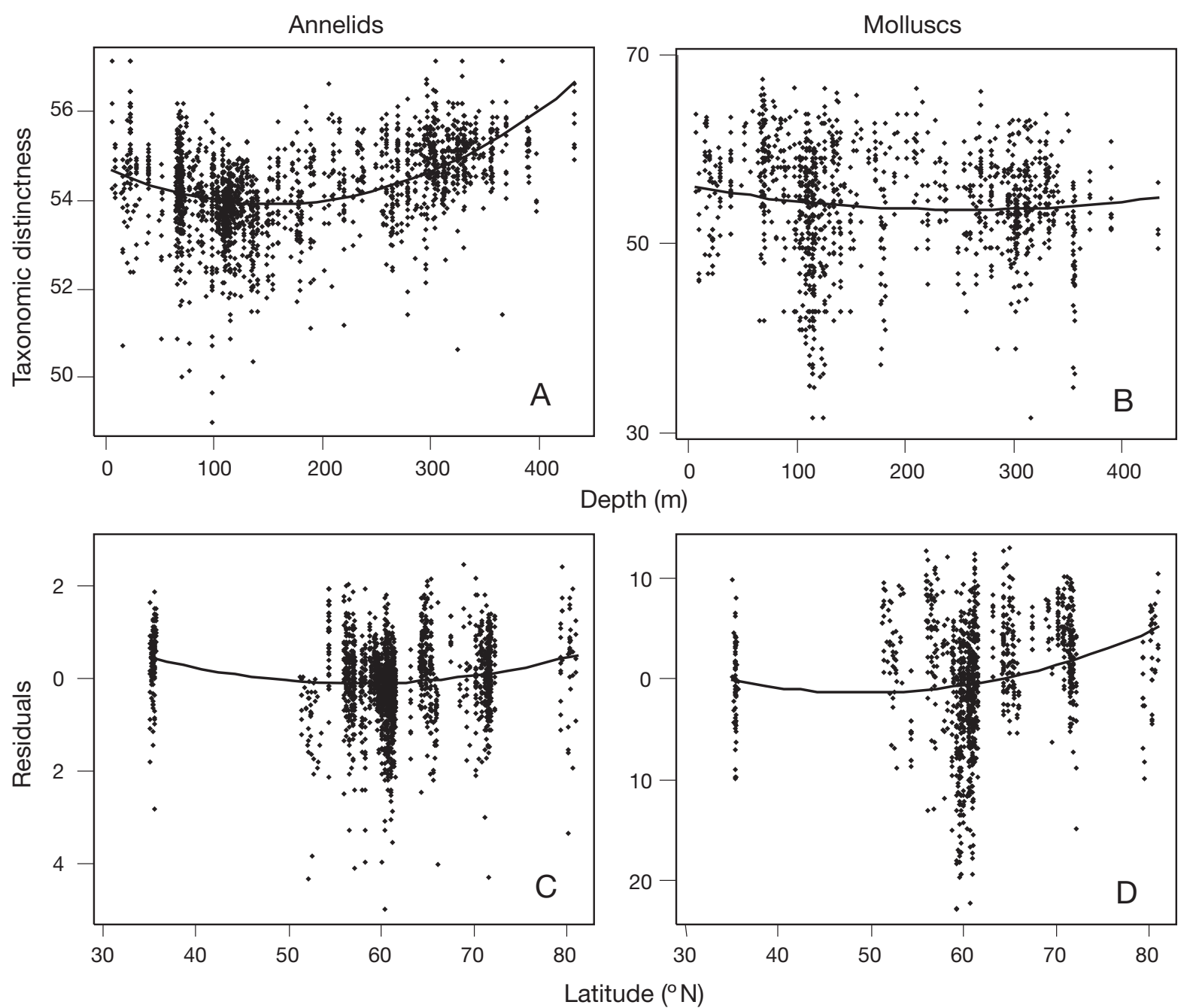

Fig. 7. $(A, B)$ Average taxonomic distinctness against depth and $(C, D)$ residuals from this relationship plotted against latitude for $(A, C)$ annelids and $(B, D)$ mollusks. Fitted lines from polynomial regressions

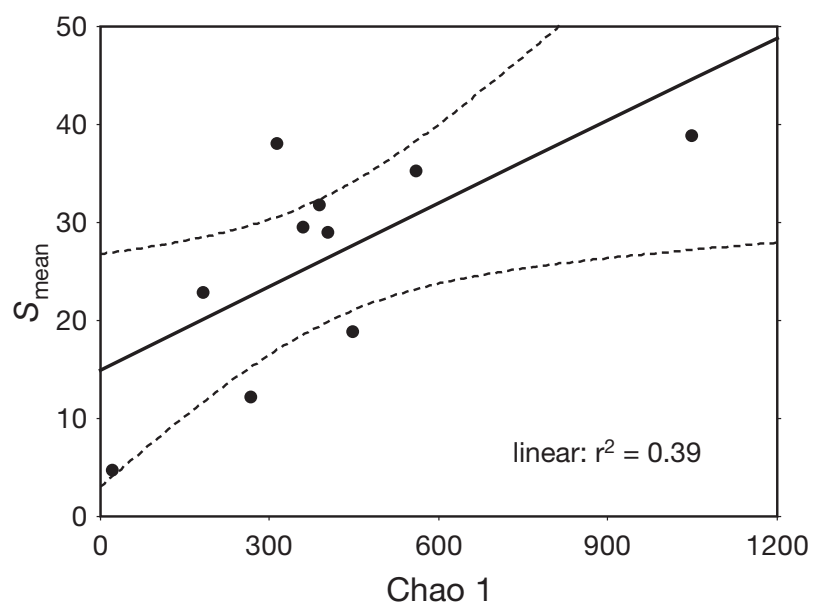

Fig. 8. Regional diversity (Chao1) against the mean species richness $\left(S_{\text {mean }}\right)$ per dataset. Dashed lines: $95 \%$ confidence intervals plying communities along the Norwegian continental shelf or the French Mediterranean coast. It is not clear whether investigations of continental-scale patterns encompassing multiple regional species pools should be expected to find trends or mechanisms from the smaller scale to be relevant. There is no environmental gradient consistent with latitude over this geographical range, and no a priori reason to suspect that factors responsible for determining biodiversity in one region would be applicable over the entire European continental shelf. Perhaps testing the latitudinal speciesdiversity gradient paradigm should then be left to empirical (e.g. the present study) and meta-analytical studies (e.g. Willig et al. 2003, Hillebrand 2004) that 'sample' over a domain spanning multiple regional species pools. Identifying patterns for entire communities or for major taxonomic groups at this scale may be the best first step in determining mechanisms responsible for generating and maintaining biodiversity. 
Patterns observed for the entire community were also seen in the 3 dominant taxonomic groups (mollusks, annelids, and crustaceans), although mollusk diversity exhibited a positive trend with increasing latitude with a higher $\mathrm{r}^{2}$ of around 0.2 (Fig. 5, Table 4). It has been proposed that calcification is energetically costly at low temperatures, possibly resulting in lower diversity of mollusks and foraminiferans toward the poles (Clarke 1992). We see no evidence to support this idea in our data, and in fact see an opposite pattern. The similarity of responses among the different groups is somewhat surprising following the recent suggestion that diversity of different functional groups may vary differently across latitudinal gradients (Roy et al. 2000, Valentine et al. 2002, Ellingsen et al. 2005). It is possible that characteristic responses of different subsets of the community were masked by treating each group without regard to functionality of component taxa. Each taxon could be further dissected in effort to identify which components contributed to the diversity at different latitudes (e.g. Roy et al. 2000).

Two additional spatial patterns in biodiversity were observed: (1) The well-known low diversity of the Baltic Sea was confirmed (Fig. 3). While low salinity excludes some taxa and thus affects species diversity, Bonsdorff (2006) suggested that low diversity in the Baltic in general is not due to an inherent property of the Baltic environment (low salinity, reduced water exchange, etc.), but instead to its ecological youth. Only 8000 yr ago it was completely glaciated and it is being recolonized slowly (see discussion in Bonsdorff 2006). More than $40 \%$ of the individuals included in the present analyses were sampled during intensive studies of the Baltic, but removing them from the analysis resulted in virtually identical results (Table 3, Fig. 4). This suggests that these data did not bias our results, and that the patterns we observed are robust to exclusion of even such a large subset of the data. (2) We see a higher point diversity (grab-level) at stations north of about $50^{\circ} \mathrm{N}$ than in datasets from more temperate areas (Fig. 3). Much of this, however, be due to the depth covariate, as the trend toward increasing diversity at high latitudes is less clear when this is taken into account (Fig. 4). Increased sampling across a wider depth range at these high-latitude areas would help clarify this.

Whereas the present study does not test specific hypotheses regarding mechanisms responsible for generation or maintenance of diversity, the patterns observed may aid in validation or refutation of some of the prevailing ideas. As mentioned in the Introduction, a major hypothesis explaining observed declines in diversity with latitudes north of the equator, and an absence of this decline toward the Antarctic continent, suggests that recent glaciation in the Arctic has led to a younger fauna that relies on recolonization from the south, and limited speciation in recent millennia, compared to the extensive and geologically old Southern Ocean (e.g. Gray 2001). We see little evidence for a strong cline from 36 to $81^{\circ} \mathrm{N}$, and the taxonomic distinctness data suggest equally diverse clades in the highest-latitude fauna, which is presumably geologically younger. Ecological mechanisms, from primary productivity and hydrographical events to sediment grain-size patchiness, have been invoked for explaining local and regional differences in diversity (e.g. Roy et al. 1998, Deubel 2000, Levin et al. 2001, MacPherson 2002). We do not have accompanying data on these parameters for our sampling stations, but these may be fruitful areas of future research into causes of diversity patterns. Finally, diversity can vary within an area - or at the same location - over decadal time scales. Climate variability affects benthic community structure, including biodiversity parameters (e.g. Kröncke et al. 1998, Beuchel et al. 2006), largely through the effect of temperature. Regional temperature changes can then affect both physical (e.g. stratification) and biological (e.g. primary production) parameters impacting reproduction, recruitment, and persistence in the system. These findings also suggest potential mechanisms acting on regional scales.

While a unimodal depth-diversity relationship with a peak in diversity between 2000 and $3000 \mathrm{~m}$ is well supported in the deep-sea literature (reviewed in Rex 1981, Levin et al. 2001), 2 recent studies conducted along depth transects in the North Atlantic and Arctic have failed to identify such a trend (Włodarska-Kowalczuk et al. 2004, Renaud et al. 2006). In the present study, we found that water depth explained over $20 \%$ (and up to $40 \%$ ) of the variability in community diversity measures, and had contrasting effects for different components of the community. We also found a unimodal response with peak diversity $\left(S\right.$ and $\left.E\left[S_{50}\right]\right)$ and reduced average taxonomic distinctness $\left(\Delta^{+}\right)$from quadratic fits between 200 and $250 \mathrm{~m}$ depth. It is unclear what could explain such a pattern across the narrow depth range of the continental shelf. Explanations for observed variability of diversity with water depth range from disturbance frequency and food supply (Levin et al. 2001), to sediment properties (Etter \& Grassle 1992), to an artifact of constrained species range boundaries (mid-domain effect, Colwell et al. 2004). Additionally, site-specific factors may play a role, since the only deep shelf stations are at the northern end of the latitudinal range. The contrast between $S$ and $\Delta^{+}$indicates that there are more species in the middle of the range, but they are more closely related to each other, lending some weight to the possibility of either the mid-domain artifact interpretation, or some local 'hot spot' of biological diversity. We have no evidence to support or discount any of these possibilities. 


\section{MacroBen database: strengths and caveats}

It is only through the vision of contributors to and managers of MarBEF's MacroBen database that this analysis is possible. The sampling density, geographical range, and habitat distribution of the data allow indepth studies of many questions regarding biodiversity in European waters. Subsets of the database can be analyzed to test for sensitivity to specific components (e.g. Table 3), or for methodological biases. Specific actions taken to achieve such a database are described in more detail in Vanden Berghe et al. (2009).

Despite all these efforts, the database is not perfect. Any dataset is biased in what it includes and what it excludes. Confining our study to the European continental shelf excludes the apparently more diverse western Atlantic basin (MacPherson 2002). Component datasets, many of which have been the subject of site-specific biodiversity publications, represent non-random and non-regular sampling. Another issue arising in the present study is that not all latitudinal zones were sampled across their entire depth range (Table 2), and samples were not available from all latitudes. This likely resulted in under-sampling of diversity from deeper areas at the south and shallower areas further north. Although we were able to control for some of this bias statistically (e.g. Fig. 4), it is not possible to completely factor out the potential biological significance of a water-depth covariate from sections of the latitudinal range where, for example, water depths $>100 \mathrm{~m}$ were not sampled. Additionally, sediment parameters may vary among sites, even if water depth is controlled for. These issues will have to be addressed further when more datasets are added to the European benthic database.

A second potential problem is the effect of unequal sampling density across the gradient range. We show that the number of species identified per degree of latitude is influenced by the area and number of individuals sampled per degree. Residual analysis and multiple linear regression, however, indicated no trend in $\gamma$-diversity with latitude after correction for sampling effort (Fig. 1B,D, and 'Results'). This is in agreement with our results for $\alpha$-diversity (Figs. $2 \& 4$, Table 3), suggesting that sampling-effort differences did not bias our results. Furthermore, $\Delta^{+}$is relatively samplesize independent (Warwick \& Clarke 2001), and similar patterns were apparent in analyses of this measure. Most studies evaluating the presence of a latitudinal gradient in diversity use point or station $(\alpha)$ diversity measures to address regional diversity questions (e.g. Gray 2002). Our results show that mean $\alpha$ (point) diversity for each dataset was positively correlated with regional diversity estimates for that dataset (Fig. 8). While we do not necessarily imply a causal relation- ship, it does show that $\alpha$-diversity patterns may be suitable for investigating regional-scale patterns.

\section{Biodiversity research: future directions and needs}

The present study highlights the importance of using large databases to answer questions across regional spatial scales. Such databases have been lacking, but this is being addressed through international cooperation coordinated by organizations such as MarBEF and the Census of Marine Life (CoML). These efforts must be continued in order to address similar questions, whether they be investigating trends in different habitats, on temporal scales, or in other regions of the world's oceans.

Progress in macroecology has been rapid in recent years (e.g. Brown 1995, Blackburn \& Gaston 2003), and focus has shifted from identifying patterns in regional diversity to determining the processes underlying the patterns (Gaston \& Blackburn 2000). Willig et al. (2003) showed that we are still far from distinguishing among the many proposed mechanisms that may be responsible for geographical patterns in diversity. However, a fundamental prerequisite to any such mechanistic analysis is to document the patterns in a robust fashion. The present study provides such an input into future studies of diversity gradients in the European soft-sediment marine benthic fauna. Importantly, our results mean that any mechanism predicting strong latitudinal gradients in diversity in these taxa may not be valid.

Studies conducted over long periods of time and at large spatial scales would be invaluable in aiding the transition from describing pattern to elucidating process. One promising avenue would be to expand the recolonization study underway in the Baltic Sea by Bonsdorff (2006) and follow the system as it develops, with carefully designed studies and targeted research questions. Such studies, combined into databases such as those analyzed here, will help to instill a more data-driven, hypothesis-led approach to marine biodiversity studies. The need for such studies gains urgency as the effects of human activities on natural systems become apparent at ever-larger spatial scales (Chapin et al. 2000).

Acknowledgements. We are grateful for the inspiration and motivation provided by C. Arvanitidis. Preparation of this paper was supported in part by Akvaplan-niva. T.J.W. acknowledges support from the Leverhulme Trust. We thank 4 reviewers for comments that improved the manuscript. The authors acknowledge the support of the MarBEF Network of Excellence 'Marine Biodiversity and Ecosystem Functioning' which is funded by the Sustainable Development, Global Change and Ecosystems Programme of the European Community's Sixth Framework Programme (contract no. GOCE-CT-2003-505446). This publication is contribution no. MPS-09014 of MarBEF. 


\section{LITERATURE CITED}

Attrill MJ, Stafford R, Rowden AA (2001) Latitudinal diversity patterns in estuarine tidal flats: indications of a global cline. Ecography 24:318-324

Azovsky A (2000) Concept of scale in marine ecology: linking the words or the worlds? Web Ecol 1:28-34

Beuchel F, Gulliksen B, Carroll ML (2006) Long-term patterns of rocky bottom macrobenthic community structure in an arctic fjord (Kongsfjorden, Svalbard) in relation to climate variability (1980-2003). J Mar Syst 63:35-48

Blackburn TM, Gaston KJ (eds) (2003) Macroecology: concepts and consequences. Blackwell, Oxford

Bonsdorff E (2006) Zoobenthic diversity-gradients in the Baltic Sea: continuous post-glacial succession in a stressed ecosystem. J Exp Mar Biol Ecol 330:383-391

Boucher G, Lambshead PJD (1995) Ecological biodiversity of marine nematodes in samples from temperate, tropical, and deep-sea regions. Conserv Biol 9:1594-1604

Brown JH (1995) Macroecology. University of Chicago Press, Chicago, IL

Chapin FS, Zavaleta ES, Evlner VT, Naylor RL and others (2000) Consequences of changing biodiversity. Nature 405: $234-242$

Clarke A (1992) Is there a latitudinal diversity cline in the sea? Trends Ecol Evol 7:286-287

Clarke A, Crame JA (2003) The importance of historical processes in global patterns of diversity. In: Blackburn, TM, Gaston KJ (eds) Macroecology: concepts and consequences. Blackwell, Oxford, p 130-151

Clarke A, Lidgard S (2000) Spatial patterns of diversity in the sea: bryozoan species richness in the North Atlantic. J Anim Ecol 69:799-814

Clarke KR, Gorley RN (2006) Primer v6: user manual/tutorial. Primer-E, Plymouth

- Clarke KR, Warwick RM (1998) A taxonomic distinctness index and its statistical properties. J Appl Ecol 35:523-531

Colwell RK (1997) EstimateS: statistical estimation of species richness and shared species from samples, Version 5. Users guide and application. Department of Ecology and Evolutionary Biology, University of Connecticut, Storrs, CT

Colwell RK, Rahbek C, Gotelli NJ (2004) The mid-domain effect and species richness patterns: What have we learned so far? Am Nat 163:E1-E23

$>$ Crame JA (1997) An evolutionary framework for the polar regions. J Biogeogr 24:1-9

Crame JA (2000) Evolution of taxonomic diversity gradients in the marine realm: evidence from the composition of recent bivalve faunas. Paleobiology 26:188-214

Crame JA (2001) Taxonomic diversity gradients through geologic time. Divers Distrib 7:175-189

Culver SJ, Buzas MA (2000) Global latitudinal species diversity gradient in deep-sea benthic foraminifera. Deep-Sea Res I 47:259-275

- Dauvin JC, Kendall M, Patterson G, Gentil F, Jirkov I, Sheader M, De Lange M (1994) An initial assessment of polychaete diversity in the northeastern Atlantic Ocean. Biodiversity Lett 2:171-181

Deubel H (2000) Structures and nutritional requirements of macrozoobenthic communities in the area of the Lomonosov Ridge in the Arctic Ocean. Ber Polarforsch 370:1-147

Ellingsen KE (2001) Biodiversity of a continental shelf softsediment macrobenthos community. Mar Ecol Prog Ser 218:1-15

Ellingsen KE, Gray JS (2002) Spatial patterns of benthic diversity: Is there a latitudinal gradient along the Norwegian continental shelf? J Anim Ecol 71:373-389
Ellingsen KE, Clarke KR, Somerfield PJ, Warwick RM (2005) Taxonomic distinctness as a measure of diversity applied over a large scale: the benthos of the Norwegian continental shelf. J Anim Ecol 74:1069-1079

Etter RJ, Grassle JF (1992) Patterns of species diversity in the deep sea as a function of sediment particle size diversity. Nature 360:576-578

Gage JD (2004) Diversity in deep-sea benthic macrofauna: the importance of local ecology, the larger scale, history and the Antarctic. Deep-Sea Res II 51:1689-1708

> Gage JD, Lambshead PJD, Bishop JDD, Stuart CT, Jones NS (2004) Large-scale biodiversity pattern of Cumacea (Pericarida: Crustacea). Mar Ecol Prog Ser 277:181-196

Gaston KJ, Blackburn TM (2000) Pattern and process in macroecology. Blackwell, Oxford

> Grassle JF, Maciolek NJ (1992) Deep-sea species richness: regional and local diversity estimates from quantitative bottom samples. Am Nat 139:313-341

Gray JS (2001) Antarctic marine benthic biodiversity in a worldwide latitudinal context. Polar Biol 24:633-641

Gray JS (2002) Species richness of marine soft sediments. Mar Ecol Prog Ser 244:285-297

> Hawkins BA, Diniz-Filho JAF, Weis AE (2005) The middomain effect and diversity gradients: Is there anything to learn? Am Nat 166:E140-E143

Heip C, Basford D, Craeymeersh JA, Dewarumez JM and others (1992) Trends in biomass, density and biodiversity of North Sea macrofauna. ICES J Mar Sci 49:13-22

> Hillebrand H (2004) Strength, slope and variability of marine latitudinal gradients. Mar Ecol Prog Ser 273:251-267

Huston M (1979) A general hypothesis of species diversity. Am Nat 113:81-101

Karakassis I, Machias A, Pitta P, Papadopoulou KN and others (2006) Cross-community congruence of patterns in a marine ecosystem: Do the parts reflect the whole? Mar Ecol Prog Ser 310:47-54

Kendall M (1996) Are Arctic soft-sediment macrobenthic communities impoverished? Polar Biol 16:393-399

> Kendall M, Aschan M (1993) Latitudinal gradients in the structure of macrobenthic communities: a comparison of Arctic, temperate and tropical sites. J Exp Mar Biol Ecol 172:157-169

Kröncke I, Dippner JW, Heyen H (1998) Long-term changes in the macrofaunal communities off Norderney (East Frisia, Germany) in relation to climate variability. Mar Ecol Prog Ser 167:25-36

> Lambshead PJD, Tietjen J, Ferrero T, Jensen P (2000) Latitudinal diversity gradients in the deep-sea with special reference to North Atlantic nematodes. Mar Ecol Prog Ser 194:159-167

Lambshead PJD, Tietjen J, Moncrieff CB, Ferrero T (2001) North Atlantic latitudinal diversity patterns in deep-sea marine nematode data: a reply to Rex et al. Mar Ecol Prog Ser 210:299-301

Lambshead PJD, Brown CJ, Ferrero T, Mitchell NJ, Smith CR, Hawkins LE, Tietjen J (2002) Latitudinal diversity patterns of deep-sea marine nematodes and organic fluxes: a test from the central equatorial Pacific. Mar Ecol Prog Ser 236: 129-135

Levin LA, Etter RJ, Rex MA, Gooday AJ and others (2001) Environmental influences of regional deep-sea species diversity. Annu Rev Ecol Syst 32:51-93

MacPherson E (2002) Large-scale species-richness gradients in the Atlantic Ocean. Proc R Soc Lond B 269:1715-1720

Mokievsky V, Azovsky A (2002) Re-evaluation of species diversity patterns of free-living nematodes. Mar Ecol Prog Ser 238:101-108 
Quinn GP, Keough MJ (2002) Data analysis and experimental design for biologists. Cambridge University Press, Cambridge

R Development Core Team (2005) R: a language and environment for statistical computing. R Foundation for Statistical Computing, Vienna. Available at www.R-project.org

Rees HL, Eggleton JD, Rachor E, Vanden Berghe E (eds) (2007) Structure and dynamics of the North Sea benthos. ICES Coop Res Rep 288:1-258 pp

Renaud PE, Ambrose WG, Vanreusel A, Clough LM (2006) Nematode and macrofaunal diversity in central Arctic Ocean benthos. J Exp Mar Biol Ecol 330:297-306

Rex MA (1981) Community structure in the deep-sea benthos. Annu Rev Ecol Syst 12:331-353

Rex MA, Stuart CT, Hessler RR, Allen JA, Sanders HL, Wilson GDF (1993) Global-scale latitudinal patterns of species diversity in the deep-sea benthos. Nature 365:636-639

Rex MA, Stuart CT, Coyne G (2000) Latitudinal gradients of species richness in the deep-sea benthos of the North Atlantic. Proc Natl Acad Sci USA 97:4082-4085

Roy K, Jablonski D, Valentine JW, Rosenberg G (1998) Marine latitudinal diversity gradients: tests of causal hypotheses. Proc Natl Acad Sci USA 95:3699-3702

Roy K, Jablonski D, Valentine JW (2000) Dissecting latitudinal diversity gradients: functional groups and clades of marine bivalves. Proc R Soc Lond B 267:293-299

Solan M, Raffaelli DG, Paterson DM, White PCL, Pierce GJ (2006) Marine biodiversity and ecosystem function: empirical approaches and future research needs. Mar Ecol Prog Ser 311:175-178

Storch D, Davies RG, Zajicek S, Orme CDL and others (2006) Energy, range dynamics and global species richness patterns: reconciling mid-domain effects and environmental determinants of avian diversity. Ecol Lett 9: 1308-1320

Svavarsson J, Stomberg JO, Brattegard T (1993) The deep-

Submitted: July 5, 2008; Accepted: February 6, 2009 sea asellote (Isopoda, Crustacea) fauna of the northern seas: species composition, distributional patterns and origin. J Biogeogr 20:537-555

Thorson G (1957) Bottom communities (sublittoral or shallow shelf). In: Hedgepeth JW (ed) Treatise on marine ecology and paleoecology. Geological Society of America, New York, p 461-534

Valentine JW, Roy K, Jablonski D (2002) Carnivore/noncarnivore ratios in northeastern Pacific marine gastropods. Mar Ecol Prog Ser 228:153-163

Vanden Berghe E, Claus S, Appeltans W, Faulwetter S and others (2009) Description of an integrated database on benthic invertebrates of European continental shelves: a tool for large-scale analysis across Europe. Mar Ecol Prog Ser 382:225-238

Warwick RM, Clarke KR (2001) Practical measures of marine biodiversity based on relatedness of species. Oceanogr Mar Biol Annu Rev 39:532-543

Willig MR, Kaufman DM, Stevens RD (2003) Latitudinal gradients of biodiversity: patterns, process, scale, and synthesis. Annu Rev Ecol Syst 34:273-309

Witman JD, Etter RJ, Smith F (2004) The relationship between regional and local diversity in marine benthic communities: a global perspective. Proc Natl Acad Sci USA 101: 15664-15669

Włodarska-Kowalczuk M, Kendall MA, Węsławski JM, Klages M, Soltwedel T (2004) Depth gradients of benthic standing stock and diversity on the continental margin at a high-latitude ice-free site (off Spitsbergen, $79^{\circ} \mathrm{N}$ ). DeepSea Res I 51:1903-1914

Włodarska-Kowalczuk M, Sicinski J, Gromisz S, Kendall MA, Dahle S (2006) Similar soft-bottom polychaete diversity in Arctic and Antarctic marine inlets. Mar Biol 151:607-616 doi:10.1007/s00227-006-0496-9

Zapata FA, Gaston KJ, Chown SL (2005) The mid-domain effect revisited. Am Nat 166:E144-E148

Proofs received from author(s): March 17, 2009 